\title{
Oxidant and Carbonyl Stress-Related Apoptosis in End-Stage Kidney Disease: Impact of Membrane Flux
}

\author{
Valeria Bordoni ${ }^{a}$ Marta Piroddic ${ }^{c}$ Francesco Gallic Massimo de Cal ${ }^{a}$ \\ Monica Bonello ${ }^{a}$ Petras Dimitri $^{a}$ Gabriella Salvatori $^{a}$ Rattanarat Ranishta $^{a}$ \\ Nathan Levin ${ }^{d}$ Ciro Tetta $^{a}$ Claudio Ronco ${ }^{a-d}$ \\ a Department of Nephrology, San Bortolo Hospital, Vicenza, ' ${ }^{b}$ Centro Studi 'Ennio Valente', Associazione Amici \\ del Rene, Vicenza, and ${ }^{\mathrm{C}}$ Department of Biochemistry, University of Perugia, Perugia, Italy; ${ }^{\mathrm{d}}$ Renal Research \\ Institute, Beth Israel Medical Center, New York, N.Y., USA
}

\section{Key Words}

Peripheral blood mononuclear cell · Advanced

oxidation protein product $\cdot$ Membrane flux

\begin{abstract}
Apoptosis is a highly regulated process which mostly affects cell-mediated immunity. In this open-label, randomized, prospective clinical study, we determined the impact in 10 hemodialysis patients treated with high-, medium-, and low-flux membranes on spontaneous or plasma-induced apoptosis, on monocytes, as well as on oxidant and carbonyl stress. High- and medium-flux membranes significantly reduced patients' plasma-dependent proapoptotic activity on U937 monocytic cell lines. Patients who had the highest levels of plasma-induced proapoptotic activity exhibited the highest plasma levels of advanced oxidation protein products (AOPPs) and carbonyls. Plasma carbonyl residues but not AOPPs were significantly lowered. Finally, a significant correlation could be drawn between the extent of plasma-induced proapoptotic activity and both plasma carbonyl and AOPP levels.
\end{abstract}

Copyright (C) 2006 S. Karger AG, Basel

\section{Introduction}

The uremic syndrome results in the progressive accumulation of a broad spectrum of toxins, due to failure of the kidney to eliminate these substances. Under normal conditions, the glomerular filter clears molecules with a molecular weight up to $\pm 58,000 \mathrm{Da}$. All these substances are supposed to be retained in renal failure and are candidate uremic toxins. The uremic toxins are classified according to their physicochemical characteristics that influence their dialytic removal: small water-soluble compounds, middle molecules and protein-bound compounds [1-3]. Ninety compounds are known as uremic toxins; 68 of them have a molecular weight $<500 \mathrm{Da}$ (small water-soluble compounds), 22 a molecular weight $>500 \mathrm{Da}$ (middle molecules), and 25 solutes $(27.8 \%)$ are protein bound.

End-stage renal disease (ESRD) patients often present with a state of immunodeficiency which may manifest as lymphopenia, impaired polymorphonuclear leukocyte function, increased susceptibility to infections, poor response to vaccinations and suppressed delayed hypersensitivity $[4,5]$. Apoptosis is a highly regulated process [6], which mostly affects cell-mediated immunity, involving lymphocytes and monocytes, which play important roles in the immunologic defense of the host [7]. Recruitment,

\section{KARGER}

Fax +4161306 1234 E-Mail karger@karger.ch www.karger.com 
Table 1. Study design

\begin{tabular}{lllll}
\hline Random order & Week 1 & Week 2 & Week 3 & Patients \\
\hline Polysulfone & Low flux & Medium flux & High flux & 5 \\
Cellulose triacetate & Low flux & Medium flux & High flux & 5 \\
\hline
\end{tabular}

During the second session of each week, blood was collected 10 min after dialysis start and $10 \mathrm{~min}$ before treatment end.

balanced by constitutive cell death through apoptosis, is important in maintaining the homeostasis of immunocompetent cells. Several studies have implicated a remarkable dysfunctional apoptotic state and/or response in ESRD patients. Accelerated peripheral blood mononuclear cell (PBMC) apoptosis and high levels of proinflammatory cytokines indicate a state of cell activation and sustained, chronic inflammation [8]. So far, all studies performed have unanimously described enhanced apoptosis and correlated it to systemic inflammation, to backfiltration of contaminated dialysis fluid, and to the biocompatibility of the dialyzer membrane. Accumulation of oxidatively damaged proteins, lipids and nucleic acids as a consequence of oxidant and carbonyl stress may induce cytokine production leading to enhanced apoptosis $[9,10]$. On the other hand, inflammatory mediators such as prostaglandins may induce apoptosis through the activation of the peroxisome proliferator-activated receptor- $\gamma$, a member of the ligand-activated nuclear receptor superfamily that plays a role in mediating differentiation of adipocytes and regulating fat metabolism [11].

In ESRD, no information exists on whether hemodialysis (HD) with membranes of different fluxes may affect apoptosis and to what extent a reduction in oxidant and carbonyl stress may be associated with a restored 'normal' apoptotic response.

The purpose of this study was to determine the impact of HD with high-, medium-, and low-flux Fresenius polysulfone and high-flux cellulose triacetate membranes on spontaneous or plasma-induced apoptosis on monocytes as well as on oxidant and carbonyl stress.

\section{Methods}

\section{Study Design}

An open-label, randomized, prospective clinical study was conducted in $10 \mathrm{HD}$ patients treated for 3 consecutive weeks with different membrane materials and fluxes (table 1). In the second week, midweek blood samples were collected before dialysis start and 10 min before treatment end. The monocytes from the patients were collected to determine spontaneous apoptosis. Plasma was used to incubate U937 cell lines (see below) and to asses the advanced oxidation protein products (AOPPs) and carbonyl compounds.

\section{Subjects}

The mean age of the HD group was $44 \pm 13$ years $(6$ males, 4 females). Patients with diabetes, signs of infection or of illness, hospital admission within the previous 6 months of enrolment or under immunosuppressive therapy were excluded. Patients were on a thrice weekly dialysis schedule of $4 \mathrm{~h}$ duration via arteriovenous fistula. A blood flow rate of $300 \mathrm{ml} / \mathrm{min}$ and dialysate flow of $500 \mathrm{ml} / \mathrm{min}$ were standard.

Five healthy volunteers were used as control group, with a mean age of $46 \pm 8$ years ( 6 males, 4 females).

\section{U937 Culture}

U937 cells, a human monocytic line, were cultured in RPMI 1640 medium supplemented with $10 \%$ heat-inactivated fetal calf serum, $2 \mathrm{~m} M L$-glutamine, $100 \mathrm{IU} / \mathrm{ml}$ penicillin and $100 \mathrm{mg} / \mathrm{ml}$ streptomycin, and kept in a controlled atmosphere $\left(5 \% \mathrm{CO}_{2}\right)$ incubator at $37^{\circ} \mathrm{C}$. Cell viability was $99 \%$ assessed by trypan blue exclusion.

U937 cells were incubated $\left(0.5 \times 10^{6} / \mathrm{ml}\right)$ with 50\% RPMI 1640 medium (with $2 \mathrm{mM} L$-glutamine, $100 \mathrm{IU} / \mathrm{ml}$ penicillin and $100 \mathrm{mg} / \mathrm{ml}$ streptomycin) and 50\% plasma.

\section{Peripheral Mononuclear Human Cell}

PBMCs were isolated from heparinized blood, using the standard procedure, i.e. Ficoll-Hypaque gradient density (Pharmacia Biotech, Sweden). After three washes, PBMCs were seeded on plates and isolated by 1-hour adherence. PBMCs were cultured in RPMI 1640 medium supplemented with $10 \%$ heat-inactivated fetal calf serum, $2 \mathrm{~m} M L$-glutamine, $100 \mathrm{IU} / \mathrm{ml}$ penicillin and $100 \mathrm{mg} /$ $\mathrm{ml}$ streptomycin, and kept in a controlled atmosphere $\left(5 \% \mathrm{CO}_{2}\right)$ incubator at $37^{\circ} \mathrm{C}$ for $96 \mathrm{~h}$. Cell vitality was checked after each PBMC purification by trypan blue exclusion.

\section{Evaluation of Apoptosis}

\section{Analysis of DNA Morphological Changes}

Apoptosis was characterized by DNA fragmentation, showing a ladder-like pattern, and nuclear fragmentation in several smaller fragments ranging in number from 2 to $>20$ cells.

Cells were stained with $10 \mu \mathrm{M} / \mathrm{ml}$ Hoechst 33342 (Sigma Chemical Co., St. Louis, Mo., USA) for $15 \mathrm{~min}$ at $37^{\circ} \mathrm{C}$, and nuclear morphology was assessed under a fluorescence microscope. Apop- 


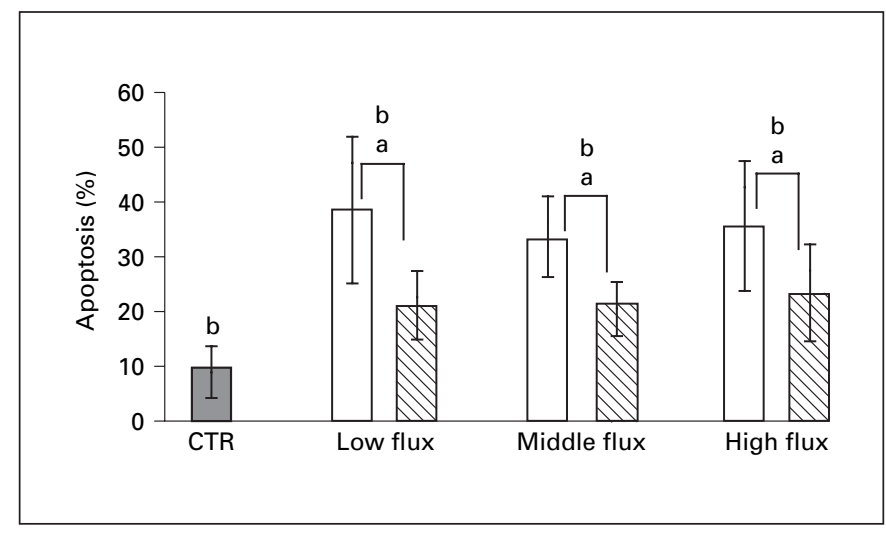

Fig. 1. Effect of membrane fluxes on monocyte apoptosis collected from the patients. Results are expressed as mean percentage of cell apoptosis. After $96 \mathrm{~h}$ of incubation, with each membrane used, monocyte apoptosis from HD patients was significantly decreased at the end of dialysis compared with the beginning ( $\left.{ }^{\mathrm{a}} \mathrm{p}<0.05\right)$; ${ }^{\mathrm{b}} \mathrm{p}<0.05$, control (CTR) versus HD. $\square=$ Predialysis; $\mathbb{\mathbb { N }}=$ postdialysis.

tosis was expressed as percent of the total cell population, counting at least 300 cells in at least 6 random selected fields [10].

\section{Determination of Caspase 3 Activity}

U937 cells and monocytes were assayed for activation of caspase 3 , an effector caspase able to cleave various cytoplasmic or nuclear substrates which leads to many morphological features of apoptotic cell death. The cells were resuspended in $50 \mu \mathrm{l}$ cell lysis buffer (Chemicon International, Temecula, Calif., USA) for $10 \mathrm{~min}$ on ice. Cell lysates were cleared by centrifugation for $3 \mathrm{~min}$ at $10,000 \mathrm{~g}$. Fifty microliters of $10 \mathrm{~m} M$ DTT and $5 \mu \mathrm{l}$ of the $4 \mathrm{mM}$ Asp-Glu-Val-Asp-p-nitroanilide substrate were added [12]. After $2 \mathrm{~h}$ of incubation at $37^{\circ} \mathrm{C}$ in the dark, the samples were read at $405 \mathrm{~nm}$ in a microplate reader. The activity of caspases was determined as a fold increase comparing the absorbance of samples with the absorbance of an uninduced control culture.

\section{Determination of $A O P P S$}

AOPPs were measured by spectrophotometry and calibrated with chloramine-T solutions (Sigma) that in the presence of potassium iodide absorb at $340 \mathrm{~nm}$. Four hundred microliters of plasma diluted $1 / 5$ in PBS and $40 \mu 1$ of acetic acid were mixed and calibrated versus the standard reference of $400 \mu \mathrm{l}$ chloramine- $\mathrm{T}$ solution $(0-100 \mu \mathrm{mol} / \mathrm{l})$ with $40 \mu \mathrm{l}$ of acetic acid and $20 \mu \mathrm{l}$ of potassium iodide. The absorbance of the reaction mixture was read at $340 \mathrm{~nm}$ against a blank containing $400 \mu \mathrm{l}$ of PBS, $20 \mu \mathrm{l}$ of potassium iodide, and $40 \mu \mathrm{l}$ of acetic acid. AOPP concentrations were expressed as micromoles per liter of chloramine-T equivalents $[13,14]$.

\section{Determination of Carbonyl Residues}

Samples of carbonyl residues were submitted to $10 \mathrm{~m} M$ dinitrophenylhydrazine in $2.5 \mathrm{MHCl}$ for $1 \mathrm{~h}$, followed by deproteinization with 20\% TCA. The pellet was washed three times in ethanol/ethyl

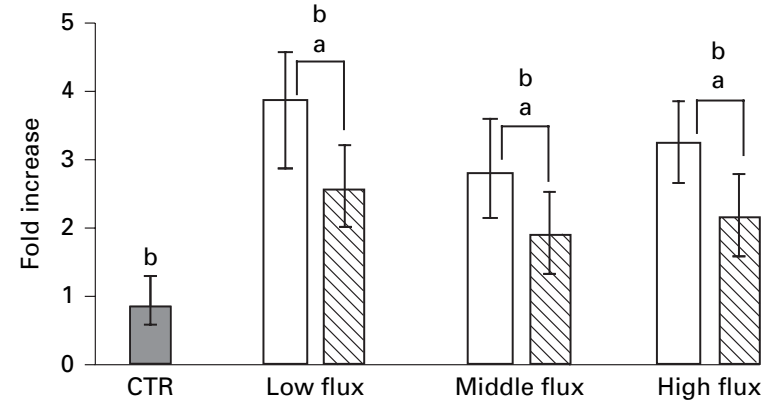

Fig. 2. Effect of membrane fluxes on caspase 3 activity of monocytes collected from the patients. Monocyte caspase 3 activity at $96 \mathrm{~h}$ incubation, with each membrane used, was significantly decreased at the end of dialysis compared with the beginning $\left({ }^{\mathrm{a}} \mathrm{p}<\right.$ $0.05)$; ${ }^{b} \mathrm{p}<0.05$, control (CTR) versus HD. $\square=$ Predialysis; $\mathbb{\mathbb { V }}=$ postdialysis. Fold increase compared with a normal control.

acetate and solubilized in $6 \mathrm{M}$ guanidine. The carbonyl concentration was measured by spectrophotometry at an optical density of $370 \mathrm{~nm}$ with $\varepsilon 370=22 \mathrm{~m} M^{-1} \mathrm{~cm}^{-1}$. The protein concentration was determined in parallel using optical density at $280 \mathrm{~nm}$ in reference to albumin [15].

\section{Statistical Analysis}

Statistical analysis was performed using the SPSS 11.5 software package. Results are expressed as means \pm SD. Statistical analyses were performed using Student's t test for coupled data. Spearman's rank order correlation coefficient (r) was used for correlation analysis. $p$ values $<0.05$ were considered significant.

\section{Results}

\section{Apoptosis of Monocytes in vitro}

Monocytes from dialysis subjects showed a marked increase in apoptosis compared with the control group $(\mathrm{p}<0.05)$. Compared with monocytes taken at the start of dialysis, there was a significant decline in apoptosis of monocytes collected at the end of dialysis $(p<0.05)$ with each membrane used (low, medium, and high flux). However, the monocyte apoptosis from patients taken at the end of HD remained higher than control monocytes (fig. 1). In parallel, the caspases correlated with the above findings (fig. 2).

Next, we examined the effect of the different dialyzer materials of membranes on monocyte apoptosis. No difference between polysulfone and cellulose triacetate 


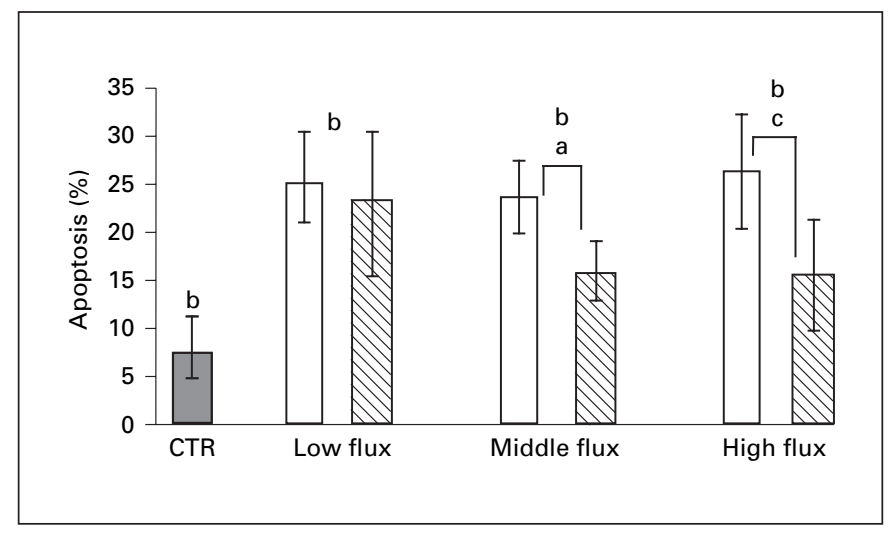

Fig. 3. Effect of plasma on U937 apoptosis. Plasma-induced apoptosis on U937 at $96 \mathrm{~h}$ incubation was significantly enhanced at the start versus the end of dialysis, but not with low-flux filters. $\square=$ Predialysis; $\mathbb{\mathbb { Q }}=$ postdialysis. ${ }^{\mathrm{a}} \mathrm{p}<0.05$, start versus end of dialysis; ${ }^{b} \mathrm{p}<0.05$, control (CTR) versus HD; ${ }^{c} \mathrm{p}<0.001$, start versus end of dialysis.

Table 2. Effect of different dialyzer material membranes on monocyte apoptosis obtained from HD patients

\begin{tabular}{lll}
\hline & Triacetate & Polysulfone \\
\hline Low flux start & $43 \pm 7$ & $35 \pm 16$ \\
Low flux end & $22 \pm 5$ & $20 \pm 8$ \\
Medium flux start & $32 \pm 7$ & $33 \pm 6$ \\
Medium flux end & $18 \pm 6$ & $20 \pm 5$ \\
High flux start & $40 \pm 7$ & $32 \pm 7$ \\
High flux end & $28 \pm 6$ & $20 \pm 5$ \\
\hline
\end{tabular}

We did not find any difference between polysulfone and cellulose triacetate membranes at similar levels of flux.

membranes were observed at similar levels of flux (table 2).

\section{Effect of Plasma on U937 Apoptosis}

U937 cells incubated with plasma were cultured for up to $96 \mathrm{~h}$. Apoptosis was evaluated every $24 \mathrm{~h}$ by fluorescence microscopy dye (Hoechst 33342). Plasma-induced U937 apoptosis was significantly enhanced in HD patients versus control $(p<0.05)$. Compared with U937 exposed to predialysis uremic plasma, there was a significant decline in apoptosis of U937 exposed to plasma collected at the end of dialysis with medium- $(p<0.05)$

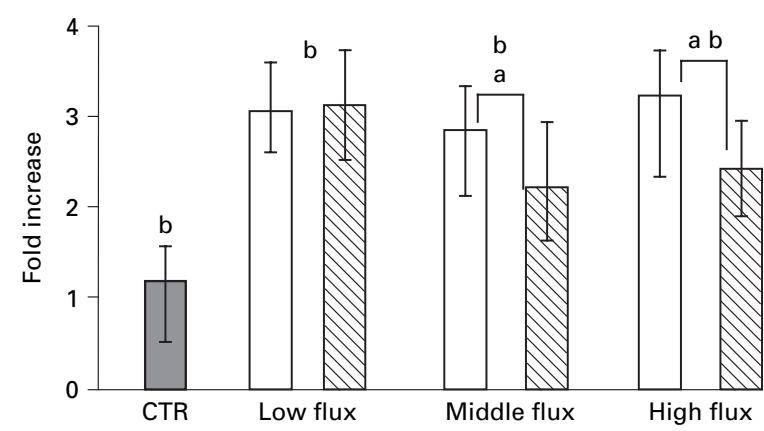

Fig. 4. Plasma-induced caspase 3 activity on U937 was significantly enhanced at the start compared with the end of dialysis, but not with low-flux filters. $\square=$ Predialysis; $\mathbb{\mathbb { N }}=$ postdialysis. ${ }^{\mathrm{a}} \mathrm{p}<0.05$, start versus end of dialysis; ${ }^{b} \mathrm{p}<0.05$, control (CTR) versus HD. Fold increase compared with a normal control.

and high-flux $(\mathrm{p}<0.05)$, but not with low-flux membranes (fig. 3).

In parallel, the caspase 3 activity measured at $96 \mathrm{~h}$ correlated with the above findings. Caspase 3 decreased at the end versus the start of dialysis using medium- $(\mathrm{p}<$ $0.05)$ and high-flux $(p<0.05)$ membranes. No differences were observed in caspase 3 activity with low-flux filters (fig. 4).

Baseline levels of these parameters (apoptosis and caspase 3 activity) were not different in low, medium, and high flux. No differences between polysulfone and cellulose triacetate membranes were observed at similar levels of flux.

Two patients were not included in the above results, as they presented a significantly different apoptotic pattern at the start of HD (U937 apoptosis at $24 \mathrm{~h}$ was $100 \%$ ) with all types of membranes (low, medium, and high flux). In both patients, apoptosis decreased at the end of dialysis only when high-flux membranes were utilized. One of these patient was in the group dialyzed with cellulose and the other in the Fresenius polysulfone group.

\section{AOPP levels}

AOPPs were highly elevated in HD patients compared with healthy subjects. There was a significant increment in AOPP levels between low-flux end and low-flux start and medium-flux end and medium-flux start. Instead, we did not find any difference between high-flux end and 
high-flux start (fig. 5). We did not observe any difference between the AOPP levels in patients treated with polysulfone and cellulose. We found that patients showing a high rate of apoptosis were the same who had significantly increased AOPP levels (table 3). There was a statistically significant correlation between U937 apoptosis and AOPP levels in these patients (Spearman's $r=0.65$; $\mathrm{p}<0.05$ ) (fig. 6).

\section{Evaluation of Carbonyl Residues}

High-flux membranes significantly reduced the total carbonyl compound levels after treatment, while there were no differences between low-flux start and low-flux end and medium-flux start and medium-flux end (fig. 7).

We did not observe any difference between levels of carbonyl residues in patients treated with polysulfone and cellulose (fig. 7).

Spearman's correlation was found for values of carbonyl residues and AOPP levels (Spearman's $\mathrm{r}=0.69$; $\mathrm{p}<0.05$ ) (fig. 8).

\section{Discussion}

Several studies have shown a dysfunctional apoptosis in patients with ESRD, and various mechanisms have been implicated, including the role of uremic toxins, dialysis-related factors, and malnutrition [2, 3, 17-20].

The present study shows that both high- and mediumflux membranes significantly reduced patients' plasmadependent proapoptotic activity on U937 monocytic cell lines. The extent at which this occurred was paralleled by a concomitant reduction in caspase 3 activity. Interestingly, patients who had the highest levels of plasma-induced proapoptotic activity exhibited the highest plasma levels of AOPPs and carbonyls. However, with high-flux membranes, plasma carbonyl residues but not AOPPs
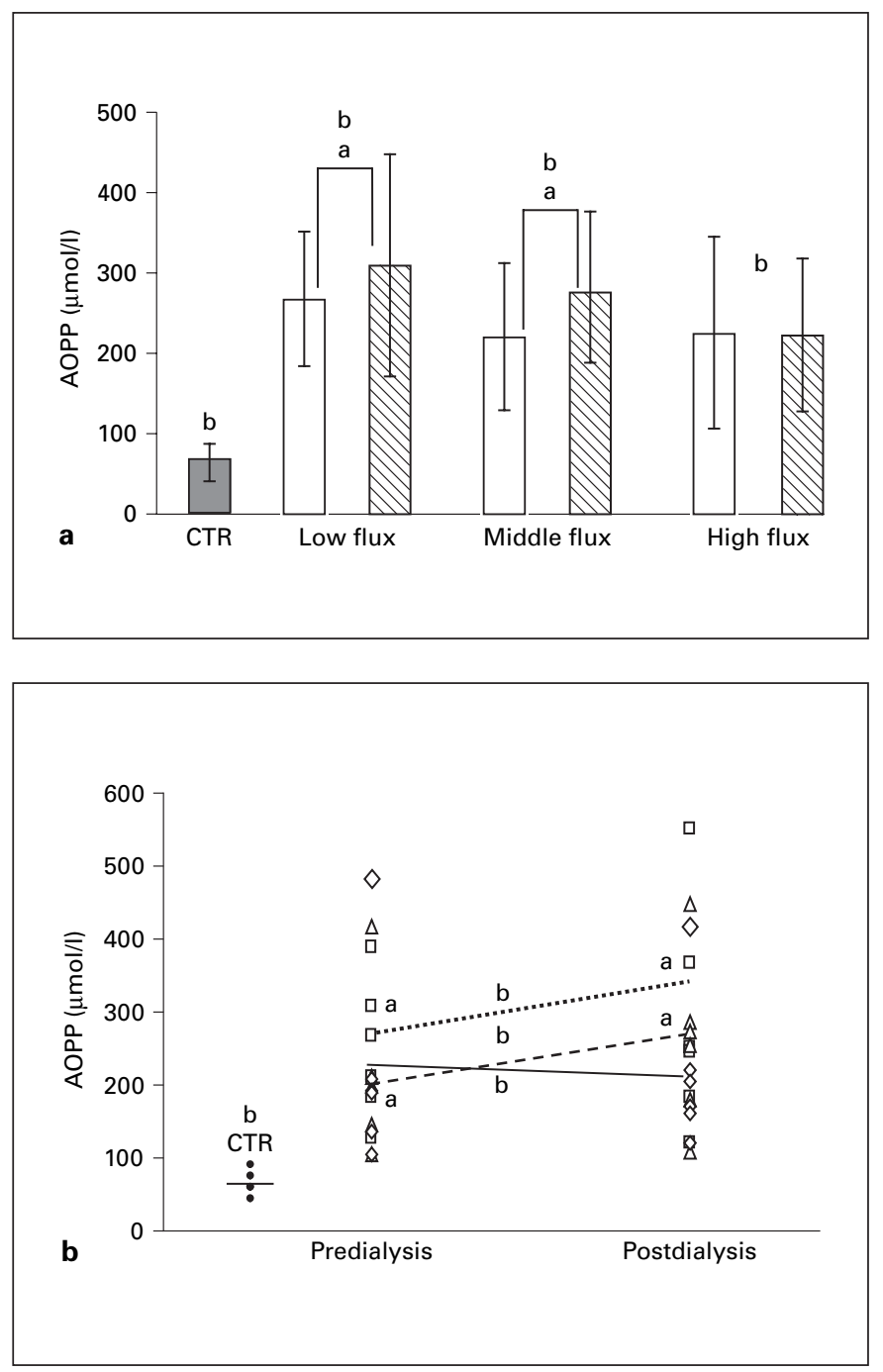

Fig. 5. AOPP levels were significantly enhanced after dialysis with low- and medium-flux filters, but not with high-flux filters. $\mathbf{a} \square=$ Predialysis; $\mathbb{\mathbb { N }}=$ postdialysis. ${ }^{\mathrm{a}} \mathrm{p}<0.05$, start versus end of dialysis; ${ }^{\mathrm{b}} \mathrm{p}<0.05$, control (CTR) versus HD. $\mathbf{b} \square=$ Low flux; $\Delta=$ medium flux; $\diamond=$ high flux. ${ }^{\mathrm{a}} \mathrm{p}<0.05$, start versus end of dialysis; ${ }^{\mathrm{b}} \mathrm{p}<0.05$, control (CTR) versus HD.
Table 3. Values of AOPPs and U937 apoptosis of 2 patients that were not included in the other results

\begin{tabular}{lcccc}
\hline & $\begin{array}{l}\text { Patient A } \\
\text { AOPP, } \mu \mathrm{mol} / 1\end{array}$ & $\begin{array}{c}\text { Patient A } \\
\text { apoptosis, \% }\end{array}$ & $\begin{array}{l}\text { Patient B } \\
\text { AOPP, } \mu \mathrm{mol} / \mathrm{l}\end{array}$ & $\begin{array}{l}\text { Patient B } \\
\text { apoptosis, \% }\end{array}$ \\
\hline Low flux start & 955.85 & 100 & $1,447.83$ & 100 \\
Low flux end & $1,256.77$ & 70 & $1,417.06$ & 100 \\
Medium flux start & $1,036.99$ & 100 & 991.88 & 100 \\
Medium flux end & 845.96 & 67 & $1,240.83$ & 100 \\
High flux start & 377.67 & 100 & 871.6 & 100 \\
High flux end & 144.37 & 7 & 372.3 & 50 \\
\hline
\end{tabular}




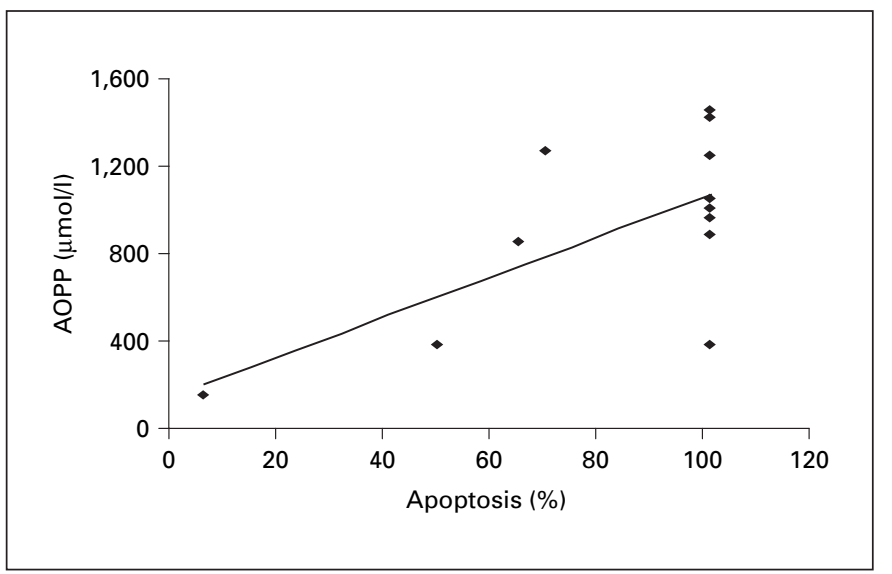

Fig. 6. Correlations between AOPP levels and U937 apoptosis in 2 patients $(\mathrm{r}=0.65 ; \mathrm{p}<0.05)$.

Fig. 7. Levels of carbonyl residues. $\mathbf{a} \square=$ Predialysis; $\mathbb{\mathbb { N }}=$ postdialysis. ${ }^{\mathrm{a}} \mathrm{p}<0.05$, start versus end of dialysis; ${ }^{\mathrm{b}} \mathrm{p}<0.05$, control (CTR) versus HD. $\mathbf{b} \square=$ Low flux; $\triangle$ = medium flux; $\diamond=$ high flux. ${ }^{\mathrm{a}} \mathrm{p}<0.05$, start versus end of dialysis; ${ }^{\mathrm{b}} \mathrm{p}<0.05$, control (CTR) versus HD.

Fig. 8. Correlations between AOPPs and carbonyl residues $(\mathrm{r}=$ $0.70 ; \mathrm{p}<0.05)$.

were significantly lowered. Finally, a significant correlation could be drawn between the extent of plasma-induced proapoptotic activity and both plasma carbonyl and AOPP levels. However, spontaneous apoptosis was
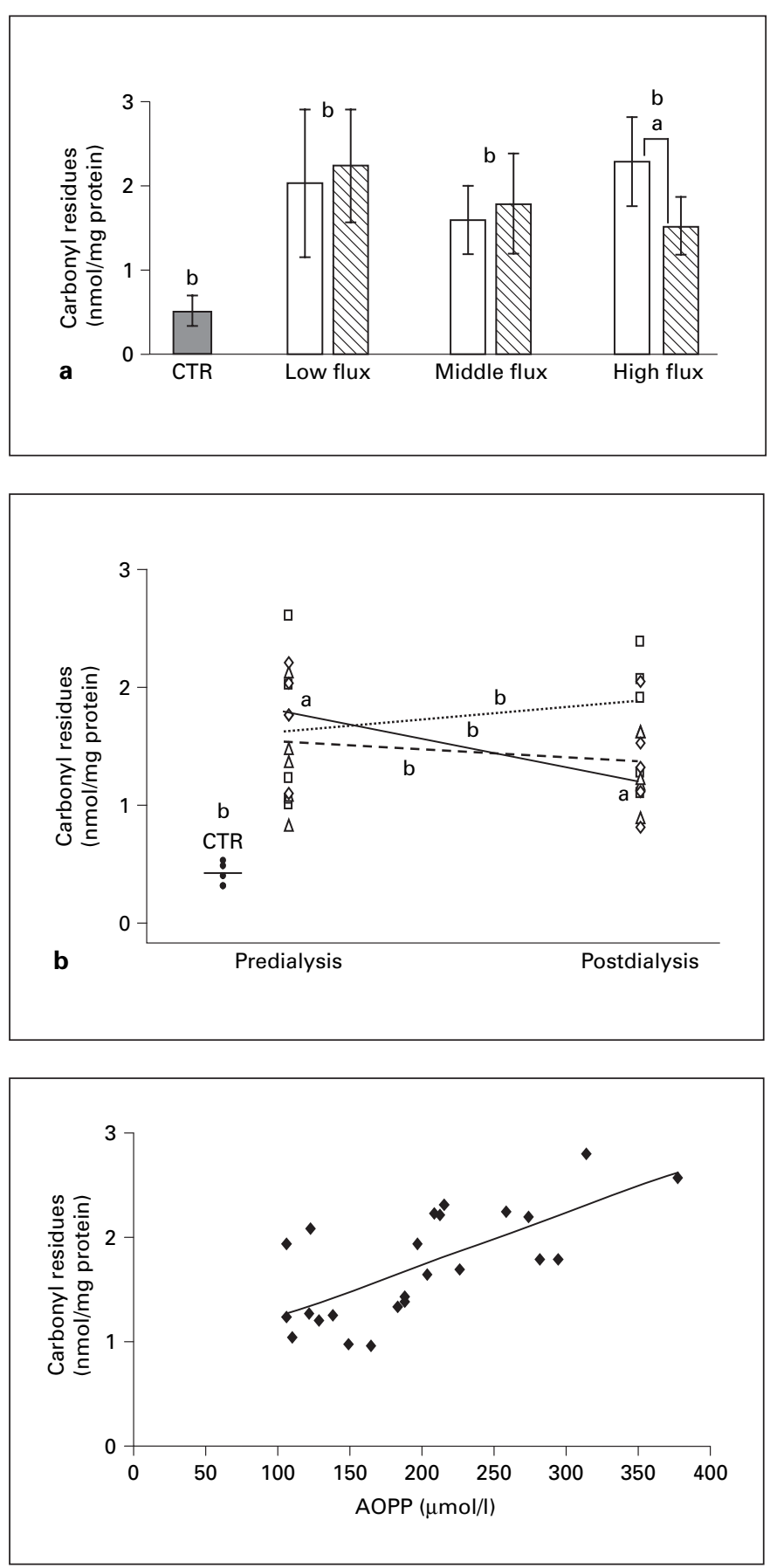

not significantly different among membranes of different fluxes.

Uremic retention appears to be a complex kinetic and multifactorial problem concerning a larger amount of sol- 
utes than those currently used as markers. Vanholder et al. [2, 3] described a large spectrum of uremic retention solutes. Small compounds with a low molecular weight are the most frequent, but do not necessarily exert toxicity. Low concentrations are found for the middle molecules; however, many of these solutes are toxic. In this study, we tried to approach the problem of uremic toxicity from a biological standpoint, studying patients' plasma (all toxins) and its effect on apoptosis. As has been demonstrated, such toxins can trigger a number of cellular responses such as apoptosis, and HD treatment may influence apoptosis rate. As working hypothesis, membranes with different fluxes and which differ in their ability to remove different uremic toxins may generate a different response to apoptosis pattern.

We reported that monocyte apoptosis at $96 \mathrm{~h}$ incubation, with each membrane used, was significantly decreased at the end of dialysis compared with the beginning. Instead, when incubating plasma with U937, we found that apoptosis was also significantly enhanced at the start compared with the end of dialysis. However, this did not happen with low-flux filters. Caspases 3 on U937 incubated with plasma correlated with apoptosis levels. No difference between polysulfone and cellulose triacetate membranes were observed at similar levels of fluxes. These results suggest that proapoptotic toxins could be middle and high molecules. Despite a significant postdialytic reduction in apoptosis and caspase activation with high and medium fluxes, in this study, baseline levels of spontaneous, plasma-induced proapoptotic activity and oxidative stress markers were not different in HD patients treated with different membranes, irrespective of their fluxes. We are aware of some limitations inherent to this study. Our design might have been too limited to detect more long-term effects. In a recent study, a single HD session did not allow to differentiate membranes with various biocompatibilities such as regenerated cellulose and polisulfone using apoptotic markers on lymphocytes and monocytes. The rather short-term study design could also explain the lack of difference between the two membranes used, i.e. polysulfone and cellulose triacetate. Using a study design which enabled to look at longterm HD patients, patients treated with regenerated cellulose had a more accelerated apoptosis than patients treated with polysulfone membranes [16]. Nevertheless, the effect of flux on the plasma-dependent proapoptotic activity with high and medium fluxes was not accompanied by any significant reduction in spontaneous apoptosis. This might be due to several factors for which the study, at the present time, offers no precise clarification: either spontaneous apoptosis is due to retention molecules that accumulate in the uremic syndrome, but which are slowly eliminated from the intracellular pool, or the mechanisms are more complex and are not or only indirectly related to soluble retention molecules. Finally, as a word of caution, although U937 cells are commonly used in studies as they are derived from a human monocytic cell line, their apoptotic response might remarkably differ from normal human monocytes.

Prospective long-term studies might disclose the benefits of high flux in patients with high levels of these oxidative compounds. Interestingly, at the start of dialysis, 2 patients showed an increased apoptosis compared with the other subjects. In both patients, apoptosis only decreased at the end of dialysis when high-flux membranes were used, suggesting that high molecular weight toxins might be at least in part responsible for enhanced apoptosis.

\section{References}

1 Boure T, Vanholder R: Biochemical and clinical evidence for uremic toxicity. Artif Organs 2004:28:248-253.

- 2 Vanholder R, De Smet R, Glorieux G, et al: Review on uremic toxins: classification, concentration and interindividual variability. Kidney Int 2003;63:1934-1943.

3 Vanholder R, Argiles A, Baurmeister U, et al: Uremic toxicity: present state of the art. Int $\mathbf{J}$ Artif Organs 2001;24:695-725.

4 Girndt M, Sester M, Sester U, Kaul H, Kohler $\mathrm{H}$ : Molecular aspects of T- and B-cell function in uremia. Kidney Int 2001;78(suppl):S206S211.
5 Pesanti EL: Immunologic defects and vaccination in patients with chronic renal failure. Infect Dis Clin North Am 2001;15:813-832.

6 Wyllie AH: Apoptosis: cell death in tissue regulation. J Pathol 1987;153:313-316.

7 Parijs LK, Abbas AK: Homeostasis and selftolerance in the immune system. Turning lymphocytes off. Science 1998;280:243-248.

-8 Schindler R, Boenisch O, Fischer C, Frei U: Effect of the hemodialysis membrane on the inflammatory reaction in vivo. Clin Nephrol 2000;53:452-459.

-9 Stadtman ER: Protein oxidation in aging and age-related diseases. Ann NY Acad Sci 2001; 928:22-38.
10 Dini L, Coppola S, Ruzittu MT, Ghibelli L: Multiple pathways for apoptotic nuclear fragmentation. Exp Cell Res 1996;223:340-347.

11 Na HK, Surh YJ: Peroxisome proliferator-activated receptor gamma (PPARgamma) ligands as bifunctional regulators of cell proliferation. Biochem Pharmacol 2003; 15:66: 1381-1391.

12 Talanian RV, Quinlan C, Trautz S, Hackett MC, Mankovich JA, Banach D, Ghayur T, Brady KD, Wong WW: Substrate specificities of caspase family proteases. J Biol Chem 1997; 272:9677-9682. 
13 Witko-Sarsat V, Friedlander M, Khoa T, Capeillere-Blandin C, Nguyen AT, Canteloup S, Dayer JM, Jungers P, Drueke T, DescampsLatscha B: Advanced oxidation protein products as novel mediators of monocyte activation in chronic renal failure. J Immunol 1998;161: 2524-2532.

14 Miyata T, Van Ypersele de Strihou C, Kurokawa K, Baynes JW: Alterations in nonenzymatic biochemistry in uremia: origin and significance of carbonyl stress in long-term uremic complications. Kidney Int 1999;55:389-399.
5 Levine RL, Garland D, Oliver CN, Amici A, Climent I, Lenz A, Ahn B, Shaltiel S, Stadtman ER: Determination of carbonyl content of oxidatively modified proteins. Methods Enzymol 1990; 186:464-478.

16 Carracedo J, Ramirez R, Soriano S, et al: Monocytes from dialysis patients exhibit characteristics of senescent cells: does it really mean inflammation? Contrib Nephrol 2005;149: 208-218.

17 Martin-Malo A, Carracedo J, Ramirez R, et al: Effect of uremia and dialysis modality on mononuclear cell apoptosis. J Am Soc Nephrol 2000;11:936-942.
18 Jaber Bl, Cendorologlo M, Balakrishnan VS, Perianayagam MC, King AJ, Pereira JB: Apoptosis of leukocytes: basic concepts and implications in uremia. Kidney Int 2001;50(suppl 78):197-205.

19 Heidenreich S, Schmidt M, Bachmann J Harrach B: Apoptosis of monocytes cultured from long-term hemodialysis patients. Kidney Int 1996;49:792-799.

20 D'Intini V, Bordoni V, Fortunato A, Galloni E, Carta M, Galli F, Bolgan I, Inguaggiato P, Poulin S, Bonello M, Tetta C, Levin N, Ronco C: Longitudinal study of apoptosis in chronic uremic patients. Semin Dial 2003;16:467473. 